\title{
Environmental sensitivity index analysis for coastal protection of oil spill in Fakfak, Papua, Indonesia
}

\author{
Utomo S.W. ${ }^{1}$, Risdianto R.K..$^{2}$, Tambunan R.P. ${ }^{1}$ and Hernawan U. ${ }^{3}$ \\ ${ }^{1}$ School of Environmental Sciences, University of Indonesia, Salemba 10430, Jakarta, Indonesia \\ 2Oil and Gas RnD Lemigas, Cipulir St. Kav 109, South Jakarta 12230, Indonesia \\ ${ }^{3}$ Center for Geological Survey, Geological Agency, Bandung 40122, West Java, Indonesia \\ Received: 14/02/2021, Accepted: 25/05/2021, Available online: 13/06/2021 \\ *to whom all correspondence should be addressed: e-mail: risdiantork@gmail.com \\ https://doi.org/10.30955/gnj.003566
}

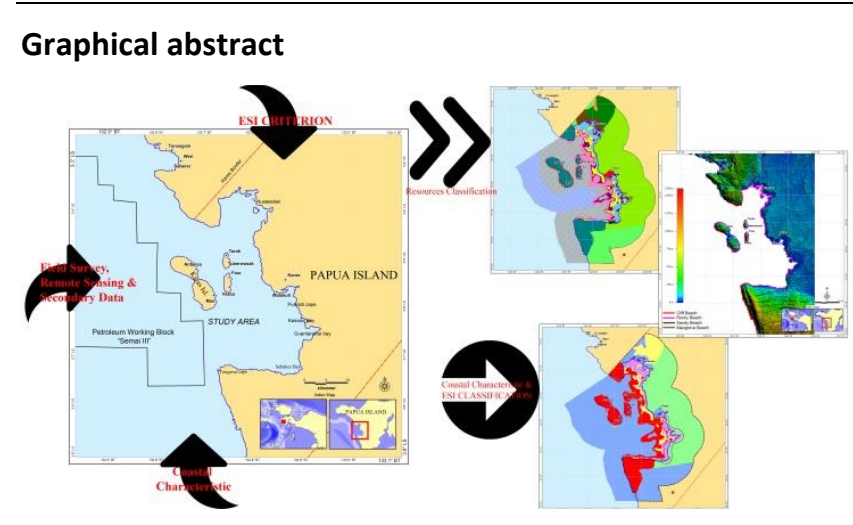

Abstract

This study was conducted to analysis of the Environmental Sensitivity Index (ESI) for anticipating the effect of oil spills on the environment in coastal areas. The study location is the coastal area and waters of the Karas District, Fakfak Regency, West Papua Province, Indonesia. The purpose of the study is to determine the priority of areas that are sensitive to oil spills. This method was carried out by scoring each unit of land based on vulnerability, conservation, and social values. ESI Analysis was carried out through geographic information systems and classified into 5 classes of sensitivity levels. The land use classification was carried out through satellite imagery and field surveys conducted in December 2018. The results of resource classification can be divided into 16 classes. The ESI analysis showed that most (51\%) were categorized as insensitive, sensitive low $24 \%$, very sensitive $15 \%$, moderately sensitive $6 \%$, and sensitive $4 \%$. Although most are not sensitive, it should be followed by effective environmental protection to maintain sustainable development.

Keywords: ESI, coastal management, conservation, vulnerable area of oil spills, vulnerability value, conservation value, social value.

1. Introduction

The coastal area of Karas District, Fakfak, West Papua Indonesia is natural ecoystem used as a source of lively hood for the surrounding community. The existence of oil and gas working block, i.e. Semai III Block (MEMR, 2018 ) in the vicinity of this location (Figure 1) raises concerns about environmental damage caused by the possibility of an oil spill. The Semai block is planning to carry out exploration drilling. The implication is that the area becomes potential to oil spill occurrences that give a significant impact on aquatic and environmental resources (Mukhtasor, 2007; Mursalin et al., 2014).

The mapping of the environmental sensitivity index (ESI) in Fakfak, Papua, Indonesia was carried out with the aim of producing an ESI map for the coastal area of Fakfak. The fact that oil spills can degrade ecosystem conditions should be taken into account in order to preserve the environment which is the basis for the survival of the ecosystem and the surrounding community. Therefore, it is necessary to respond quickly, precisely and accordingly in the event of an oil spill.

One effort to overcome oil spills is prioritizing the handling of potentially polluted areas that helps to allocate resources and it can be executed based on environmental sensitivity that reflects the reaction rate of a coastal area to recover if an oil spill disaster occurs. (Utantyo et al., 2003). Mapping the level of environmental sensitivity to oil spill events is a step in preparedness efforts, responses, and efforts to cooperate in tackling oil spills (IPIECA/IMO/OGP, 2012), essential tool/material to assist policymakers during events (IPIECA/IMO/OGP, 2012) and crucial for the most efficient implementation for the effectiveness of cleaning operations (Filho et al., 2009). ESI should be made before oil spills occur (Oyedepo and Adeofun, 2011). The ESI scale classifies coastal environments according to sensitivity relative to oil spills by approach of integrates information of coastal vulnerability, natural resources, and its utilization by the human (NOAA, 2001). 
In order to anticipate ecosystems from possible oil spills, it is necessary to conducts environmentally planning and studies by mapping the Environmental Sensitivity Index (Hernawan and Risdianto, 2014). The method produce ESI map that provide an overview of the level of vulnerability of an area to possible oil spills based on the level of vulnerability, conservation and social conditions of the environment and community, which is slightly different from the determination made by Souza and Filho (2009) which divides the level of vulnerability from 1 - 10 with an emphasis on physical conditions. environment.

\section{Materials and methods}

\subsection{Study location and time of research}

The research was conducted in the coastal area of the Karas district, Fakfak regency, West Papua province at coordinates $132.5^{\circ}-133.05^{\circ} \mathrm{E}$ and $3.25^{\circ}-3.8^{\circ} \mathrm{S}$ (Figure 1). The research was conducted from August 2018 until April 2019 and a field survey was conducted in December 2018.

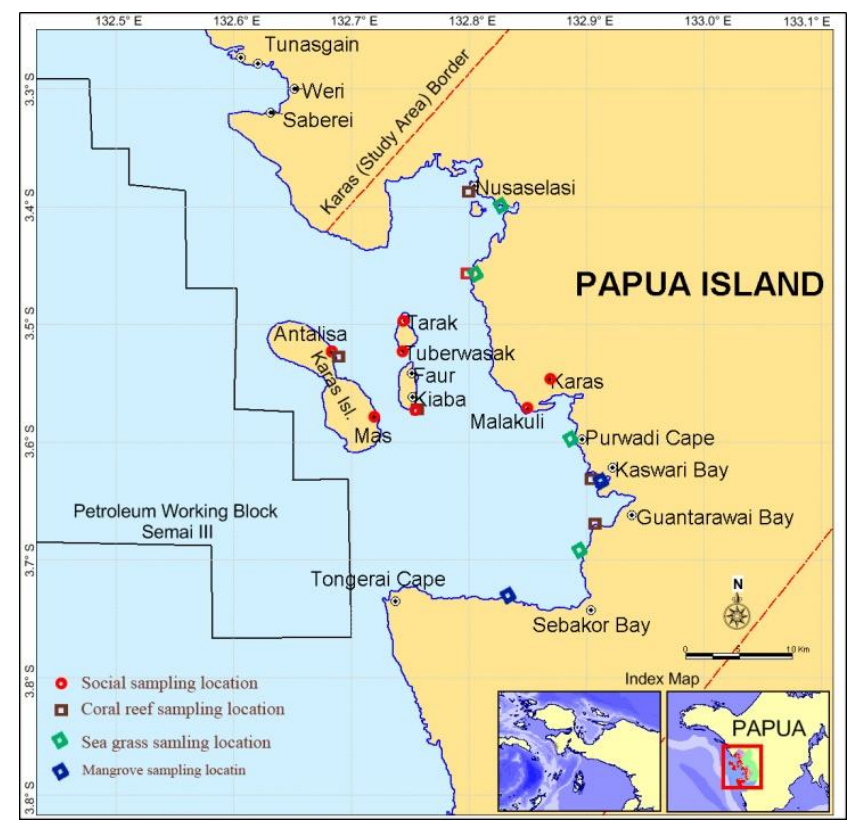

Figure 1. The study area

\subsection{Population and sample}

The population consists of coastal ecosystems with mangrove ecosystems, coral reefs, seagrass, and households or fishing families with community samples are people who work as fishermen, both capture fishermen and aquaculture fishermen.

The sampling technique for coastal ecosystem used incidental sampling and simple random sampling techniques for the community. Incidental sampling was carried out in certain areas with characteristics that are considered suitable to be sampled for mangrove ecosystems, coral reefs, seagrass and forests. Simple random sampling was carried out by questionnaire to community samples (fishermen), where samples are taken regardless of the level in the household population or fishing family. The sampling point of coral reef is 6 sampling locations, mangrove 4 locations, seagrass 4 location and social (community). The number of samples of households or families of fishermen in the research location are 7 sampel of 201 families and calculated using Slovin's formula (Almeida et al., 2010).

\subsection{Data collection}

Data collected through a) observation or field survey; namely direct observation of the ecosystem and social conditions of the community during field work b) questionnaires and interviews with community respondents who work as fishermen; where the sample was taken regardless of the level in the household population or fishermen's family. The purpose of the interview is to obtain an overview of the social conditions of the community in relation to the utilization of the existing ecosystem, so that it can be used in determining the social value of ESI and c) literature studies related to research.

\subsection{Data analysis}

Data analysis was carried out by elaborating various data using Geographical Information System (GIS), applied using the zonal or cluster method and calculated by using tabular analysis (Wardhani et al., 2011). Mangrove and seagrass analysis include visual observation of the number of species in one observation transect with a size of $10 \times 10$ meters in a large transect of $100 \times 100$ m for coral reef and size $15 \times 15$ for seagrass in order to determine the con-servation or ecological value of the resource. The status of utilization of mangrove forest was obtained through interviews with surrounding communities. Coral reefs analysis was carried out to obtain the number of species and the percentage of the live coral cover area by using formula $L(\%)=\mathrm{Li} / \mathrm{Ln}$ (English et al., 1997), where $L=$ Per-centage of coral cover (\%), $\mathrm{Li}=$ number of observation points of dominant live coral size $10 \mathrm{~m} \times 10 \mathrm{~m}, \mathrm{Ln}=$ total number of observation points in one transect size $100 \mathrm{~m} \times 100 \mathrm{~m}$. The result classified in 5 classes percentage category.

ESI analysis was carried out using an overlay modeling based on the equation developed PKSPL-IPB (1994) that adopted from Gundlach (1978), NOAA (2002), Sloan (1993), namely:

$$
\mathrm{ESI}=\mathrm{VV} \times \mathrm{CV} \times \mathrm{SV}
$$

where VV is the Vulnerability Value, CV is the Conservation Value and SV is the Social Value. Vulner-ability Value, describe the class of resources that reflect the level of vulnerability of habitat, land use, land cover affected by an activity; Conservation Value/Ecological Value, describe representativeness, unique-ness, integrity and relation-ship to other class of resources;; Social Value, describe the impact of the economy, social and culture from an activity (such as oil spill) to a class of resources. Each component has a value between $1-5$, so ESI value has values range from 1 as least sensitive to 125 as most sensitive. The ESI value divided into 5 (five) environmental sensitivity classes based on the 
distribution of values, namely $1<\mathrm{ESI}<24$ (Insensitive), $25<$ ESI < 49 (Low sensitivity), $50<$ ESI < 74 (Mod sensitivity) and $100<\mathrm{ESI}<125$ (Very sensitive).

Specifically for the vulnerability index used criteria developed by Sloan (1993) that classified several

Table 1. Ecosystem and habitat vulnerability in coastal areas

\begin{tabular}{|c|c|c|}
\hline $\begin{array}{l}\text { Vulnerability } \\
\text { Level }\end{array}$ & Category & Habitat type \\
\hline 5 & Very High & $\begin{array}{c}\text { Mangrove, brackish swamp, protected Rocky tidal areas, protected flood plain, special closure (e.g. for } \\
\text { rare species) }\end{array}$ \\
\hline 4 & High & Coral reefs, seagrass beds \\
\hline 3 & Fair & Semi-open waters (bay, pier) \\
\hline 2 & Low & Rocky beach, sandy beach \\
\hline 1 & Very Low & $\begin{array}{l}\text { Rocky upland areas open, open water (offshore), rocky subtidal (basic/rocky hard coral), soft rocky } \\
\text { subtidal }\end{array}$ \\
\hline
\end{tabular}

Source: Sloan, 1993.

\section{Results and discussion}

\subsection{Resource classes}

The results of the study showed that the resources of the study were divided into 17 classes, which are presented in Figure 2 and photograph of vulnerable ecosystem presented in Figure 3. The determination of vulnerable ecosystem was referred to Sloan, 1993 (see Table 1).

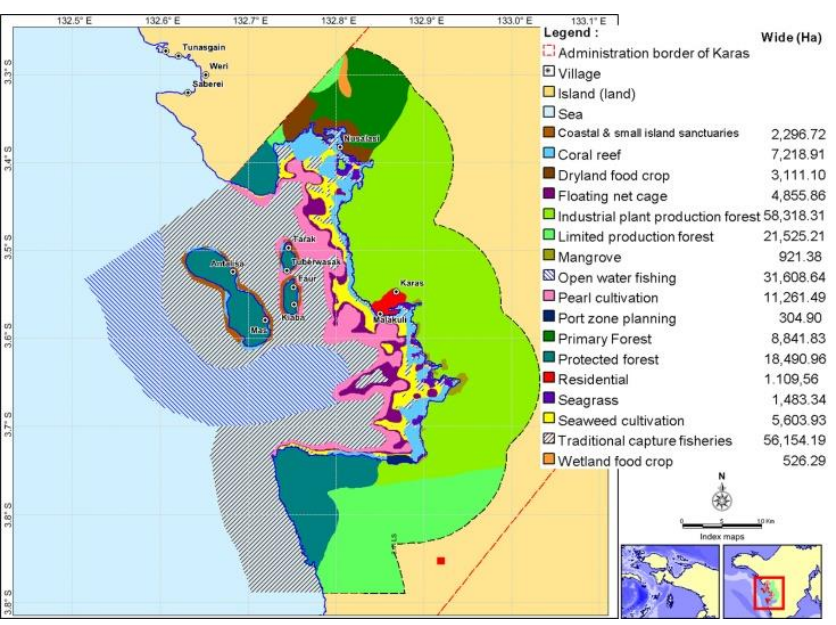

Figure 2. Coastal and aquatic resources

\subsubsection{Coral reef}

Based on the results of field observations and secondary data from the Ministry of Maritime Affairs and Fisheries (2013), the Karas district has a relatively extensive distribution of reefs, especially in coastal areas, ranging from Tanjung Tongerai to Tanjung Purkadi. The presence of coral reefs can also be seen starting from Tanjung Purkadi, especially around the Malakuli village, to the Nusaselasi region. The distribution of coral reefs was also seen around the islands of Karas, the island of Faurkiaba, and the island of Tuberwasaktarak, even though the distribution was only a little around the islands. The number of species that can be identified around the waters of the Karas district is 6 (six) species. The six species are Favia sp., Favites sp., Porites sp., Acropora sp., Seriatopora sp., and Montipora $s p$. The lowest live coral cover density is in 3 (three) habitats and coastal ecosystems that are classified as vulnerable or sensitive to pollution by oil spills (Table 1). Coastal charateristics classified base on Dolan et. al. (1975). observation locations, namely around Patirar area (27\%), waters near the village of Antalisa (25\%), and waters near the village of Kiaba (22\%). Live coral cover density levels with moderate levels were observed in 2 (two) locations, namely in the southern part of the Malakuli village (39\%) and waters around the Nusaselasi area (25\%). The area around the waters southwest of Malakuli village was observed to have a high level of live coral cover density (42\%).

\subsubsection{Mangrove}

Mangroves around the Karas district spread from the Gurantarawai bay coast to the Malakuli coastal waters. There are 4 (four) species of mangrove found around the Karas district, namely Avicennia sp., Bruguiera sp., Rhizophora $s p$., and Soneratia $s p$. The dominant mangrove species is Rhizophora sp.

\subsubsection{Seagrass}

The presence of seagrass in the Karas district is spread from the area around the Gurantarawai bay coast to the Malakuli coastal waters and around the Nusaselasi coastal waters. The species found at the research sites in Karas district were 5 (five) types, namely Syrongodium $s p$., Cymodosea sp., Enhalus sp., Thalassia sp., and Halophila sp. Enhalus sp. is seagrass species that have the most widespread and dominant distribution.

\subsubsection{Fishery}

Fisheries in Karas district generally are sea cucumbers, shark fins, flying fish eggs, lobsters, crabs, and groupers. Most of the fishermen use traditional fishing gear to catch live groupers. There are two types of fishing in the Karas district, namely fishing in the open sea and traditional fishing areas. Traditional fishing areas can be in the form of floating net cages that are not too far from the coastline. The marine product cultivation area in the Karas district covers the area of seaweed cultivation and pearl shells. Aquaculture is generally carried out in waters near the coast. 


\subsubsection{Forest and land resources}

Forest resources include limited production forest areas and industrial plantations, while cultivation land resources include wetlands and dry land. Industrial plantation areas were observed on the large island of Papua starting from around the area east of Tanjung Murak to the north around the Nusaselasi area. A limited production forest area was observed in the south of Tanjung Murak. The area of dry land food crops was observed around Nusaselasi to the northwest. Whereas, the area of wetland food crops is in the north of Nusaselasi with a relatively small area.

\subsubsection{Protected areas}

Protected areas in the study area consist of nature reserves and primary forests in mountainous or hilly areas with the status of land use as protected forests. Protected forest areas in the study area was observed around Tanjung Tongerai-Tanjung Murak, north of Nusaselasi, Karas island, Faurkiaba island, and Tuberwasaktarak island. Other protected areas in the research area in the Karas district are beach sanctuaries.

\subsubsection{Tourism area}

Tourism potentials in this area include white sand beaches on the coast of Tanjung Tongerai and maritime adventure tourism locations such as diving, special interest tours for research on coral reef ecosystems in the area around the Tanjung Tongerai coastline, Tanjung Murak, Gurantarawai bay, Kaswari bay, and Nusaselasi.
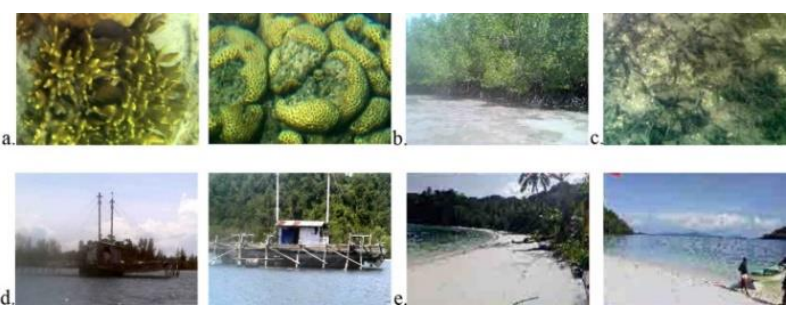

Figure 3. The vulnerable ecosystem in the study area (a) coral reef, (b) mangrove, (c) seagrass, (d) floating net cage, and (e) tourism area

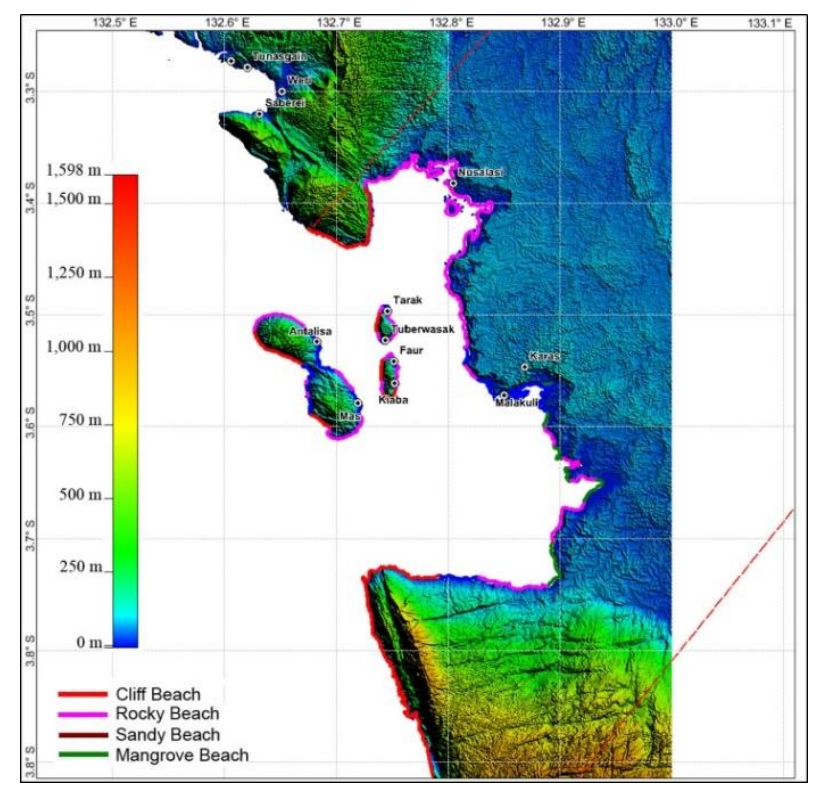

Figure 4. Coastal Characteristic of the study area

\subsection{Coastal characteristic}

Coastal characteristics of the study area (Figure 4) can be divided into four types, namely: 1) cliff beach, which is characterized by rugged coastal rock and cliff that reflect moderate-steep slope, utilize as protected/conservation forest and a part of small island sanctuaries. This coastal type located in the southern and northern part of the study area and Karas isles, 2) rocky beach, which characterized with boulder, rock with low-moderate slope, 3) mangrove beach, which characterized by low slope morphology and covered by mangrove vegetation, and 4) sandy beach, which characterized by sand beach with low-moderate slope. In some area is as a sandy narrow pocket beach. Some area utilizes as tourist area (white sand beach), settlement, and harbor development. The settlement area directly facing the sea has narrow sandy beaches.



Figure 5. Environmental sensitivity index classification

\subsection{Environmental sensitivity index}

The results of the ESI based on the classification of equations (i) with normal distribution indicate the sensitivity level of the study area can be divided into five classes, namely very sensitive, sensitive, moderately sensitive, low sensitive, and insensitive (Figure 5). Table 2 shows the resume of VV, SV, SV, and ESI values of resources in the area.

An area categorized as "very sensitive" and "sensitive", including an area that has special values, both ecologically and economically, should get priority to be protected and managed. This sensitive area can be in the form of a natural area that includes ecosystems, habitats both in the waters or land, and areas that have substantial economic value and or can interfere with the livelihoods of the surrounding communities. Areas that classified as "very sensitive" and "sensitive" in this research are very vulnerable to damage if exposed to pollutants from oil and gas industry activities such as oil spills. This area must get a priority because they can affect the presence of other biological resources such as biota in the vicinity. Humans who live around these areas will also be affected both from the health and socioeconomic aspects, either directly or indirectly. The area is categorized as "very sensitive" and "sensitive" because it has a high value of vulnerability, ecological or conservation, and socio-economic value. 
The criteria for highly sensitive areas in this region especially protected forests and coastal borders or small island sanctuaries, are related to the existence of stringent management and are limited by the existence of applicable regulations and laws issued by the central government and regional governments. Also, there are stringent regulations made by local communities based on the agreement in force in the area. Floating net cages (FNC) are "very sensitive" in the study area due to the use of particular water areas around FNC. The FNC waters areas is used for the placement and storage of fish catches which have a high economic value of the type of snapper and grouper. This commodity has a high economic value if sold alive to be sent to Bali or export to Hong Kong. As a comparison, the selling price of snapper and grouper based on information from fishing communities in the study area, if sold in living conditions the range is between IDR 280,000290,000 per kilogram. However, if it is already dead, most people will not sell it and only consume it in the area. Aquatic areas for pearl cultivation are "very sensitive" criteria because they are related to the use of waters for particular purposes with relatively little diversity of cultured pearl shells. The process of natural pearl formation takes a long time so that this commodity has a very high selling value. So that if it experiences damage or failed cultivation if it is exposed to pollutants by oil and gas industry activities, it will be difficult to recover and it takes a relatively long time to adjust the physical and chemical conditions of the waters to re-establish pearl farming activities.

Table 2. Resume of VV, CV, SV, and ESI class of resources

\begin{tabular}{|c|c|c|c|c|c|c|c|}
\hline ID & Type of resource classes & VV & CV & SV & ESI & Sensitivity level & ESI Class \\
\hline 1 & Coastal and small island sanctuaries & 5 & 5 & 5 & 125 & High sensitivity & 5 \\
\hline 2 & Coral reef & 4 & 3.5 & 5 & 70 & Moderate sensitivity & 3 \\
\hline 2 & Coral reef & 4 & 4 & 5 & 80 & Sensitive & 4 \\
\hline 3 & Dryland food crop & 5 & 3 & 1 & 15 & Insensitive & 1 \\
\hline 4 & Floating net cage & 5 & 5 & 5 & 125 & High sensitivity & 5 \\
\hline 5 & Industrial plant production forest & 3 & 2 & 5 & 30 & Low sensitivity & 2 \\
\hline 6 & Limited production forest & 3 & 1 & 5 & 125 & Insensitive & 1 \\
\hline 7 & Mangrove & 5 & 4 & 5 & 100 & Sensitive & 4 \\
\hline 8 & Open water fishing & 1 & 4 & 5 & 20 & Insenstive & 1 \\
\hline 9 & Pearl cultivation & 5 & 5 & 5 & 125 & High sensitivity & 5 \\
\hline 10 & Port zone planning & 3 & 1 & 5 & 15 & Insensitive & 1 \\
\hline 11 & Primary forest & 3 & 5 & 5 & 75 & Moderate sensitivity & 3 \\
\hline 12 & Protected forest & 5 & 5 & 5 & 125 & High sensitivity & 5 \\
\hline 13 & Residential of Malakuli Village & 5 & 1 & 4 & 20 & Insensitive & 1 \\
\hline 13 & Residential of Tarak Village & 5 & 1 & 4 & 20 & Insensitive & 1 \\
\hline 13 & Residential of Kiaba Village & 5 & 1 & 3.5 & 17.5 & Insensitive & 1 \\
\hline 13 & Residential of Faur Village & 5 & 1 & 3.75 & 18.75 & Insensitive & 1 \\
\hline 13 & Residential of Antalisa Village & 5 & 1 & 3.75 & 18.75 & Insensitive & 1 \\
\hline 13 & Residential of Mas Village & 5 & 1 & 3.75 & 18.75 & Insensitive & 1 \\
\hline 13 & Residential of Tuberwasak Village & 5 & 1 & 3.5 & 17.5 & Insensitive & 1 \\
\hline 14 & Seagrass & 4 & 5 & 5 & 100 & Insensitive & 4 \\
\hline 15 & Seaweed cultivation & 5 & 3 & 5 & 75 & Moderate sensitivity & 3 \\
\hline 16 & Traditional capture fisheries & 1 & 4 & 5 & 20 & Insensitive & 1 \\
\hline 17 & Wetland food crop & 4 & 1 & 1 & 4 & Insensitive & 1 \\
\hline
\end{tabular}

Note : 1) The difference in conservation value (CV) for coral reef is based on the difference in the percentage of live coral cover.

2) The difference in social value (SV) of residential areas is due to differences in social conditions in the area, namely the number of houses, work force, supporting facilities, and economic infrastructure.

Some areas which classified as sensitive to coral reefs, mangrove forests and seagrass in the study area are related to ecosystem vulnerability, conservation values or ecological values, and high socio-economic values. This type of resource is three interconnected ecosystems in supporting the ecological balance system in the territorial waters. Mangrove forest ecosystems are a source of nutrient or nutrient supply for coastal areas and are indicators of coastal fertility. The mangrove forest area is also used as a natural spawning area as well as a natural enlargement place for various types of fish because in the region there are many food sources for small fish. The function of mangrove forests is indirect for the local community (the location is not adjacent to the settlement) as well as a coastal abrasion barrier. Muarif et al. (2012) emphasize the difficulty in handling oil spill in mangrove ecosystem indicated the importance of efforts to avoid oil spills from entering into mangrove ecosystem.

The role of coral reefs and seagrass ecosystems is crucial for biota and fish in the waters, especially in terms of further development or enlargement. This ecosystem will be a supplier of food sources and natural refuge from predators before growing into adult biota and fish. Coral reef areas can be a marine tourism area that will provide high economic value and benefits for the surrounding communities. However, there are coral reef areas classified 
as "moderate sensitive" criteria because they are related to the percentage of live coral cover, which is relatively small (11\% -30\%).

The type of primary forest resources belongs to the "moderate sensitive" area because it is related to the level of vulnerability that is not too high in terms of protecting forest areas, even though the biodiversity in this region is high. Various species of vegetation, including those that are endemic, grow and develop in the area. The surrounding community searches for many types of plants and other materials such as ant nests and other types of plants as ingredients for making traditional medicines and hunting to meet their own needs (not for sale). Thus, in terms of conservation or ecological values and socio-economic values are still relatively high. The area that is classified as "moderate sensitive" is seaweed cultivation. The level of vulnerability is high because of the use of waters specifically. However, from the aspect of conservation value or ecology value is not too high because of the use of species of Gelidium sp. easily obtained by the community at the research location. However, the high dependence of some people whose livelihoods are in the field of seaweed cultivation, causes the socio-economic value of this cultivation to be significant. Poses to overcome areas that are classified as "moderate sensitive" will be the next priority after the areas that are classified as "very sensitive" and "sensitive" in the event of pollution by oil and gas industry activities.

Areas that are classified as "low sensitive" will be the next priority after handling areas that classified as "very sensitive", "sensitive", and "moderate sensitive" because the risk and damage to habitat are relatively smaller compared to areas classified as "very sensitive", "sensitive" and "moderate sensitive". Areas that are classified as "low sensitive" in the study area are production forests or industrial plantations. This area is not protected, and commercial products can be utilized economically with selective logging systems. The diversity of species that only have two types (Akasia and Meranti) causes this region to have relatively small conservation values. Also, production forest habitats or industrial plantations, which are mostly grown on land, are less likely to be exposed to pollutants if there is an impact of pollution by oil and gas industry activities.

Areas that are classified as "insensitive" will have a relatively shorter impact or even have no impact at all in response to the presence of pollutants by oil and gas industry activities. Limited types of production forest resources in the study area almost have the same character as the type of industrial plantation. The difference is only in conservation values, in the limited production forests in the study area consists of only one type of tree, Meranti. This condition distinguishes a limited production forest belonging to an "insensitive" area. The types of wetland and dryland resources belong to "insensitive" resources because they are associated with relatively low production (< IDR 14 million/year). In the study area, the products produced from the wetland area did not exist at all because there were indeed no communities farming in wetland areas such as rice or other types of wetland plants. However, in the Fakfak district spatial plan map, an appropriate area has been provided and can be used to conduct wetland cultivation business at the research site. Likewise for dry land types, generally only in the form of garden plants around the house where production is minimal and used for personal use (not sold).

The fishing area, both open sea fishing and traditional capture fisheries belong to the "insensitive" criterion and it related to relatively open water areas. So, if there is pollution due to oil and gas industry activities, pollutants will be easily dispersed, and the concentration of pollutants will decrease. The process of handling and handling pollutants is relatively faster.

Residential areas include areas classified as "insensitive". The low ESI value for settlements in the study area is because, in this area, there are no historical sites or sacred sites whose status must be protected. Although the level of a vulnerability is quite high when viewed from the aspect of residential distance from the sea which is very close $(<6$ $\mathrm{km}$ ), the contour height is relatively flat-moderate slope (025 meters), has rivers that are used by the surrounding community and relatively high socio-economic value, not making this area has a high sensitivity class.

\subsection{Discussion}

The concept of mapping coastal environments and ranking them on a scale of relative sensitivity was originated in 1976 for Lower Cook Inlet in the United States (NOAA, 2002). The ESI system is an international scheme that classifies and ranks the overall sensitivity of different coastal habitats to oil spills. (Sanjarani et al., 2015).

Environmental sensitivity level in the coastal area due to oil spill determined by three components, i.e. oil exposure, ecological sensitivity and socio-economical sensitivity (Schallier et al., 2013). Exposure of coastal ecosystem that vulnerable to oil spill implies the possibility of oil spill enter the coastal area (Tyler-Walters et al., 2001) and determined by hydro oceanographic factors. In the coastal area, there are several ecosystems that vulnerable to oil pollution. The ecosystems are mangrove, coral reef, and seagrass. The effort to resolve oil spill in mangrove is very difficult, because of difficult access to mangrove (Hoff, 2002). If vulnerable coastal ecosystem impaired ecologically, then the socio-economical function of the ecosystem will be affected also. This condition indicates that oil spill in the vulnerable area of the coastal ecosystem will lead to disruption of the component of social, economical and culture in the community that has relevance to the coastal ecosystem. Once this spill reaches the shore it creates major ecological damage (Sanjarani et al., 2015).

Areas classified as sensitive for coral reefs, mangrove and seagrass in the study area are related to ecosystem vulnerabilities, conservation values or high ecological and socio-economic values. These types of resources are three ecosystems that are interrelated in supporting the ecological balance system in water areas. Mangrove or mangrove forest ecosystems as a source of nutrient supply 
for coastal areas and become indicators of the fertility of coastal waters which are classified as sensitive according to research conducted by Sanjarani et al., 2015. The function of mangroves is indirectly for local communities (locations not close to each other) with human settlements) as well as a barrier to coastal abrasion in the research area. The role of coral reef ecosystems and seagrass beds is very important for biota and fish in the waters, especially in terms of further development or enlargement. This ecosystem will provide a source of food and a natural refuge from predators before it grows into biota and adult fish. Coral reef areas can become a marine tourism area that will provide high economic value and benefits to the surrounding community.

The distribution pattern of areas classified as very sensitive, sensitive and moderate sensitive which is a priority for countermeasures is almost spread throughout the study area. The relationship between the movement of physical oceanographic conditions (currents and waves) and the presence of areas classified as very sensitive, sensitive and moderate will provide important information in the implementation of oil and gas operations in the study area. Semi diurnal type of the the study area will affect the content of pollutants that have the potential to be exposed to areas classified as very sensitive, sensitive and moderate, especially during high tide. So it is necessary to anticipate by monitoring the condition of the tide and the direction of the currents leading to areas that are classified as very sensitive, sensitive and medium sensitive.

In order to anticipate the impact of pollution by the activities of the oil and gas industry and to protect the types of resources in areas that have a high level of sensitivity (very sensitive, medium sensitive and sensitive), it is necessary to integrate information on areas classified as prone to the movement patterns of oil spills (oil spill trajectory model) so the contingency plan and speed of handling time are more planned, faster and more efficient in the study area.

\section{Conclusion}

The environmental sensitivity index (ESI) in the study area shows that most regions are areas that are "insensitive" to oil spills, namely fishing areas, limited production forests, food crops, and settlements. Besides, the area categorized as "sensitive" and "very sensitive" count as much as 19 percent. Nevertheless, in the context of environmental protection for sustainable development, attention should be prioritized to prevent oil pollution because if there is an oil spill, the high effort needed to clean it.

\section{References}

Almeida J.V., Capistrano T.G. and Sarte G.M.F. (2010), Elementary Statistics, UP Press Philippines, Quezon City.

Dolan R., Hayden B. and Vincent M. (1977), Classification on coastal landform of the Americas in Classification of Coastal Environments, Technical Report No 14, University of Virginia, Virginia.

English S.A., Baker V.J. and Wilkinson C.R. (1997), Survey Manual for Tropical Marine Resources, Australian Institute of Marine Science, Townsville.
Filho P.W.M.S., Prost M.T.R.dC., de Miranda F.P., Sales M.E.C., Borges H.V., da Costa F.R., de Almeida E.F., Junior W.dR.N. (2009), Environmental Sensitivity Index (ESI) mapping of oil spill in the Amazon coastal zone: the Piatam mar project, Brazilian Journal of Geophysics, 27(Supl.1), 7-22.

Gundlach E.R. and Hayes M.O. (1978), Vulnerability of coastal environment to oil spill impact, Marine Technology Society Journal, 12(4), 18-27.

Hernawan U. and Risdianto R.K. (2017), Coastal protection of southern part of the Bintuni Bay from oil spill: an Environmental Sensitivity Index approach, Bulletin of the Marine Geology, 13(2), 77-88.

Hoff R., Hensel P., Proffitt E.C., Delgado P., Shigenaka G., Yender R. (2002), Oil Spill in Mangrove, Planning and Response Considerations. NOAA Ocean Service, Office of Response and Restoration.

IPIECA/IMO/OGP. (2012), Sensitivity Mapping for Oil Spill Response, The global oil and gas industry association for environmental and social issues, International Association of Oil \& Gas Producers, International Maritime Organization, London.

MEMR (Ministry of Energy and Mineral Resources) (2018), Petroleum working block in Indonesia Region, Ministry of Energy and Mineral Resources, Jakarta.

Ministry of Maritime Affairs and Fisheries (2013), Data Book and Analysis of the Preparation of Zoning Plans for Coastal Areas and Small Islands of Fakfak Regency, West Papua Province (in Bahasa), Ministry of Maritime Affairs and Fisheries, Jakata.

Muarif, Damar A., Hariyadi S., Sutrisno D., Boer M. (2016), A Framework for screening of variables of Ecological Sensitivity Index of mangrove ecosystems to oil spills, International Journal of Sciences: Basic and Applied Research, 1, 142-152.

Mukhtasor. (2007), Coastal and Marine Pollution (in Bahasa), Pradnya Paramita, Jakarta.

Mursalin, Nurjaya I.W and Effendi H. (2014), Analyze of environmental sensitivity for OSCP (Oil Spill Contingency Plan) at the southern coast of Mahakam Delta, East Kalimantan Province (in Bahasa with English abstract). Journal of Natural Resources and Environmental Management, 4(1), 84-95.

NOAA (National Oceanic and Atmospheric Administration) (2002), Environmental Sensitivity Index Guidelines, Version 3.0, NOAA Technical Memorandum NOS OR\&R 11, Washington.

NOOA (National Oceanic and Atmospheric Administration) (2001), Introduction to ESI Maps, Office of Response and Restoration, National Ocean Service, NOOA, Washington.

Oyedepo J.A. and Adeofun C.O. (2011), Environmental Sensitivity Index Mapping of Lagos Shoreline, Global NEST Journal, 13(3), 277-287.

PKSPL-IPB. (1994), Mapping of the Environmental Sensitivity Index of the Coastal Areas of Subang-Indramayu, West Java Province, Pertamina, Jakarta.

Sanjarani, M. et al. (2015), Environmental Sensitivity Index (ESI) mapping for oil spills at Strait of Hormuz, Iran. Research Journal of Fisheries and Hydrobiology, 10(9), 216-223.

Schallier R., van Roy W., and van Cappellen M. (2013), Technical Sub-report 6: Development of an Environmental and Socioeconomic Sensitivity Methodology. Be Aware, Bonn Agreement Belgium.

Sloan N.A. (1993), Various Impacts of Oil on Marine Resources. A Literature Review from Around the World that is Relevant for Indonesia, EMDIKLH, Jakarta. 
Tyler-Walters H., Hiscock K., Leur D.B., Jackson A. (2001), Identifying and ecosystem sensitivities. Report to Department for Environment, Food and Rural Affairs. From the Marine Life Information Network (MarLIN), Marine Biological Association of the United Kingdom, Plymouth. (Final Report).

Utantyo, Hartono and Sutikno. (2003), GIS Applications for Environmental Sensitivity Index Mapping Case Study in Cilacap Coastal Area and Segara Anakan), Humans and the Environment, $\mathbf{X}(3), 131-140$.

Wardhani M.K., Sulistiono and Siregar V.P. (2011), Level of the south coastal area of Bangkalan Residence on oil spill potention (in Bahasa with English abstract), Scientific Journal of Fisheries and Marine Sciences, 3(1), 13-19. 